Original Research Paper

\title{
Electrical Studies of Carboxy Methycellulose-Chitosan Blend Biopolymer Doped Dodecyltrimethyl Ammonium Bromide Solid Electrolytes
}

\author{
${ }^{1}$ Nur Yasmin Abu Bakar, ${ }^{1}$ Nur Hafiza Mr. Muhamaruesa, \\ ${ }^{1}$ Nur Ain Bashirah Aniskari and ${ }^{1,2}$ Mohd Ikmar Nizam Mohamad Isa \\ ${ }^{1}$ Department of Physics, School of Fundamental Science, Universiti Malaysia Terengganu, Malaysia \\ ${ }^{2}$ Center of Corporate Communication and Image Development, Chancellery, \\ Universiti Malaysia Terengganu, 21030 Kuala Terengganu, Terengganu Darul Iman, Malaysia
}

\author{
Article history \\ Received: 27-08-2014 \\ Revised: 02-10-2014 \\ Accepted: 12-02-2015 \\ Corresponding Author: \\ Mohd Ikmar Nizam Mohamad Isa \\ Center of Corporate \\ Communication and Image \\ Development, Chancellery, \\ Universiti Malaysia Terengganu, \\ 21030 Kuala Terengganu, \\ Terengganu Darul Iman, Malaysia \\ E-mail: ikmar_isa@umt.edu.my
}

\begin{abstract}
In this study, a polymer-blend system consist of Carboxy Methylcellulose (CMC)-Chitosan (CS) as blend biopolymer host and doped with various composition of Dodecyltrimethyl Ammonium Bromide (DTAB) were successfully prepared via solution casting techniques. The new system has been analyzed through Electrical Impedance Spectroscopy (EIS) from temperature $303 \mathrm{~K}$ until $393 \mathrm{~K}$ to determine the conductivity of biopolymer electrolytes in the frequency range of $50 \mathrm{~Hz}$ to $1 \mathrm{MHz}$ and the voltage between 5 to $50 \mathrm{mV}$. The optimum conductivity $\left(1.86 \times 10^{-6} \mathrm{~S} . \mathrm{cm}^{-1}\right)$ at ambient temperature obtained for composition of $5 \mathrm{wt} \% \mathrm{DTAB}$. The temperature dependence of ionic conductivity was found to obeys the Arrhenius rule where $\mathrm{R}^{2} \approx 1$ and thermally activated. The dielectric studies show a non-Debye behavior of SBEs based on the analyzed data using complex permittivity, $\varepsilon^{*}$ and complex electrical modulus, $\mathrm{M}^{*}$ of the sample at selected temperature.
\end{abstract}

Keywords: Solid Biopolymer Electrolytes, Dodecyltrimethyl Ammonium Bromide, Biopolymer Blend, Ionic Conductivity, Dielectric Studies

\section{Introduction}

In recent years, the electrolyte based on natural polymer has attracted great interest among the academician. The finding is to spell out the mechanism of conductivity enhancement in the systems (Wach et al., 2001; Chauhan and Lal, 2003; Jung et al., 2006; Isiklan et al., 2008; Peng and Chen, 2010). Most of natural polymer are biodegradable (Huang et al., 2003; Ramlli et al., 2013), easy to be found (Chai and Isa, 2012; Othman et al., 2012) and low in production cost (Rozali et al., 2012) comparable to the current electrolyte systems, they use heavy-metal like lead and mercury which expensive (Khurmi and Sedha, 2010), hazardous (Sit et al., 2012) and non-biodegradable (Rozali et al., 2012). In fact, the earth will run out of these materials if focused solely on it (Calvin, 1979).

Some may use synthetic polymers that derived from petroleum oil like nylon, polyethylene, Teflon, epoxy and polyester as polymer host in SBEs. Unfortunately, most of them are unsolvable in solvents and nonbiodegradable which can cause environmental problem compared to natural polymers occurs in nature, often water-based and can be extracted. For that reason, electrolyte based natural polymer has engrossed much attention due to their potential applications in electrochemical devices such as super capacitors, rechargeable batteries, fuel cells and solar cells (Buraidah and Arof, 2011).

Polymer blend is a mixture of two or more different polymers without covalent bond formation (Shukur et al., 2012). The conductivity of polymer blend is better than the single polymers (Sandoval et al., 2005). Thus, it affects the conductivity of the polymer electrolytes (Utracki, 2002).

Carboxy Methylcellulose (CMC) and Chitosan (CS) (Wan et al., 2006; Kadir et al., 2011; Bakar and Isa, 2014) biopolymer blend have been chosen incorporate as the host due to its mechanical strength and superior properties like good proton, $\mathrm{H}^{+}$acceptor from Dopant (DTAB). Hence, the miscibility of the blend with no phase separation between the two polymers has been proven to enhance the ionic conductivity of SBEs (Rajendran et al., 2002; Baskaran et al., 2006). It can form a good electrode-electrolyte surface contact, leakage free and easy for handling compared to liquid 
or gel counterparts. Hence, it affects the neatness of the production systems.

This present work aims to discover the electrolyte composition exhibits the highest ambient electrical conductivity in the systems of $\mathrm{CMC} / \mathrm{CS}$ blend biopolymer doped with DTAB solid electrolytes.

\section{Material and Methods}

\section{Sample Preparation}

About $1.3333 \mathrm{~g}$ of CMC from Acros Organic Co. with purify of $>99.9 \%$; average $\mathrm{MW}=90,000$ and $0.6667 \mathrm{~g}$ of chitosan W.A. Hamond Drierite Company LTD were dissolved in $1 \%$ of acetic acid solution (Merck). The $\mathrm{CMC} / \mathrm{CS}$ was stirred until dissolution completely achieved. Then, different composition of DTAB (Magna Value) in wt. $\%$ as dopant was added into $1 \%$ acetic acid solution and stirred. Then, the $\mathrm{CMC} / \mathrm{CS}$ solution and DTAB solution were mixed and stirred until it homogenous. The mixtures were casted into Petri dishes and dried in oven at $60^{\circ} \mathrm{C}$ until SBEs were formed. The SBEs were kept into desiccators for further drying process. Clear and transparent SBEs were obtained for characterization. The designations for SBEs doped with various wt.\% of DTAB are shown in Table 1.

\section{Electrical Impedance Spectroscopy (EIS)}

The conductivity of SBEs were analyzed by using Electrical Impedance Spectroscopy (EIS) modeled HIOKI 3532-50 LCR Hi-Tester. The machine will be interfaced to a computer in a frequency in the range of $50 \mathrm{~Hz}$ to $1 \mathrm{MHz}$. The electrolytes were cut into a suitable round size and sandwiched in between the stainless steel that act as an electrode of conductivity cell which connected by leads to computer. The bulk resistance $\left(R_{b}\right)$ was obtained from the plot of negative imaginary part $\left(Z_{i}\right)$ versus real part $\left(Z_{r}\right)$ of impedance. The conductivity of the sample was calculated from the Equation 1:

$$
\sigma=t /\left(R_{b} A\right)
$$

Where:

$A=$ Area of electrolyte-electrode contact $\left(\mathrm{cm}^{2}\right)$

$t=$ Thickness of the electrolyte $(\mathrm{cm})$ and

$R_{b}=$ Bulk resistance $(\Omega)$

Table 1. Designation for SBEs doped with various composition wt.\% of DTAB

\begin{tabular}{ll}
\hline Sample & Composition (wt.\%) \\
\hline DTAB-0 & 0 \\
DTAB-1 & 1 \\
DTAB-2 & 2 \\
DTAB-3 & 3 \\
DTAB-4 & 4 \\
DTAB-5 & 5 \\
DTAB-6 & 6 \\
DTAB-7 & 7 \\
\hline
\end{tabular}

\section{Results and Discussion}

\section{Conductivity Studies}

Conductivity, $\sigma$ versus various composition, wt. $\%$ of DTAB at ambient temperature was plotted in Fig. 1. It has been observed that the conductivity from $3.15 \times 10^{-9}$ $\mathrm{S} . \mathrm{cm}^{-1}$ increase until it achieved optimum value of $1.86 \times 10^{-6} \mathrm{~S} . c m^{-1}$ at $5 \mathrm{wt} \%$ of DTAB. It shows composition of charge carrier (DTAB) act like a catalyst towards the conductivity of electrolyte.

The increasing of ionic conductivity can be explained by the unification of ions at higher salt concentration, which leads to the enlargement formation of ion clusters and the number of charge carriers and their mobility until $\mathrm{H}^{+}$ion from DTAB has attached optimally to the vacancy in the CMC-CS biopolymer blend host bond (Shukur et al., 2012).

Afterward, the conductivity of the SBEs starts to fall after the addition of $6 \mathrm{wt} . \%$ of DTAB. According to Aziz et al. (2010) the decreasing of conductivity can be clarified by accumulation of ion that contribute to the overcrowded system, thus it conveys to the decreasing number of mobile charge carriers and limitation towards mobility ion (Selvasekarapandian et al., 2005).

Figure 2 shows the temperature dependence of conductivity for SBEs at selected temperatures. The temperature-dependence of ionic conductivity measurements were used to analyze the mechanism of ionic conduction of SBEs systems and even the small changes has been detected. According to Vieira et al. (2007), the dependence of ionic conductivity on the salt composition provides information on the specific interaction among salt and polymer matrix.

It shows that as the temperature increase, the conductivity will also increase as it proves temperature, $\mathrm{T}$ is directly proportional to the conductivity, $\sigma$ as shown in the Equation 2. According to Samsudin and Isa (2012a; 2012b) the pattern proves that the conductivity is thermally assisted. The regression value are near to 1 which is $R^{2} \approx 1$ that supported by (Samsudin et al., 2012) the temperature dependent of ionic conductivity for this complexes systems obeys an Arrhenius behavior by the expression of the Equation 2.

$\sigma=\sigma_{o} \exp \left(-E_{a} / k T\right)$

Where:

$\sigma=$ Conductivity

$\sigma_{o}=$ Pre-exponential factor

$E_{\alpha}=$ Activation energy and

$K=$ Boltzmann constant

Based on the equations that applied, the value of $E_{\alpha}$ will lower at the highest conductivity. This phenomenon 
is due to the increment of ions in the SBEs systems and the addition of DTAB that leads to the decrement of energy barrier for the ion transport that causes the reduction of $E_{\alpha}$ as shown in Fig. 3.

According to Chai and Isa (2013) the conducting ions easily excited to free ion-like state which affects the increment conductivity of Solid Biopolymer Electrolytes (SBEs) systems. The conductivity behavior of SBEs can be deeply explained from the dielectric studies where it is comes from the fundamental knowledge regarding the electrical studies of electrolytes (Chai and Isa, 2011).

\section{Dielectric Studies}

The dielectric constant is a basic knowledge in the ability of the biopolymer to disband added salts which may increase the conductivity of the electrolytes. Dielectric constant also known as stored charge in material. The loss of energy represents the dielectric loss, $\varepsilon_{i}$ which normally produces a rise in temperature of a dielectric placed in an alternating electrical field. The dielectric constant (the real part of complex permittivity, $\varepsilon_{r}$, Equation 3) and dielectric loss (the imaginary part of complex permittivity, $\varepsilon_{i}$, Equation 4) are defined as:

$$
\begin{aligned}
& \varepsilon_{\mathrm{r}}=Z_{\mathrm{i}} / \omega \mathrm{C}_{\mathrm{o}}\left(Z_{r}^{2}+Z_{\mathrm{i}}^{2}\right) \\
& \varepsilon_{\mathrm{i}}=Z_{\mathrm{r}} / \omega \mathrm{C}_{\mathrm{o}}\left(Z_{r}^{2}+Z_{\mathrm{i}}^{2}\right)
\end{aligned}
$$

where, $Z_{i}$ is the imaginary part of the complex permittivity, $Z_{r}$ is the real part of the complex permittivity, $\omega=2 \pi f(f$ is frequency) and $C_{o}=\varepsilon_{0} A / t$ ( $\varepsilon_{o}$ is permittivity of free space). The dielectric constant, $\varepsilon_{r}$ and dielectric loss, $\varepsilon_{i}$ for DTAB-5 are shown in Fig. $4 a$ and $b$.

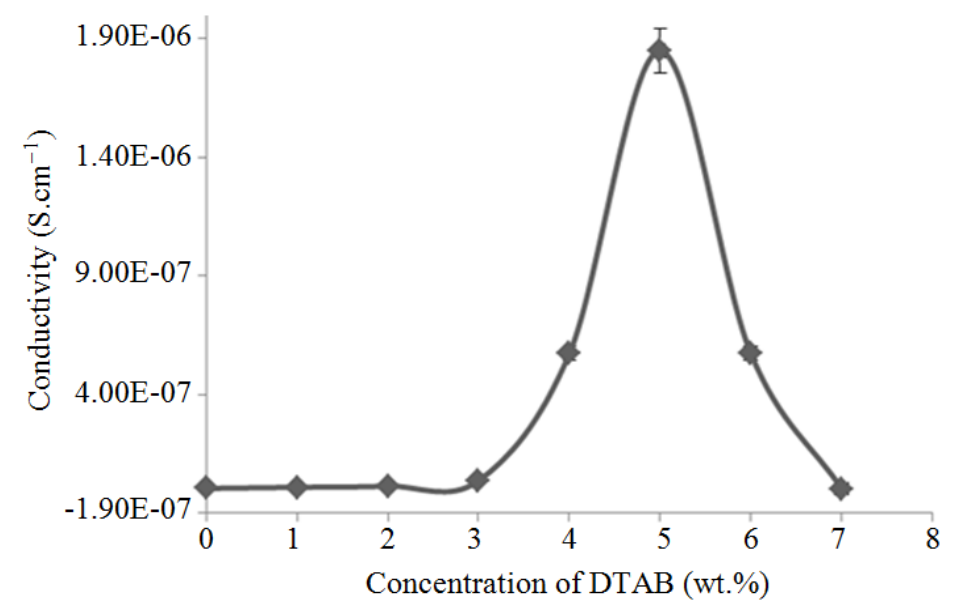

Fig. 1. Conductivity, $\sigma$ versus various composition, (in wt.\%) of DTAB at ambient temperature

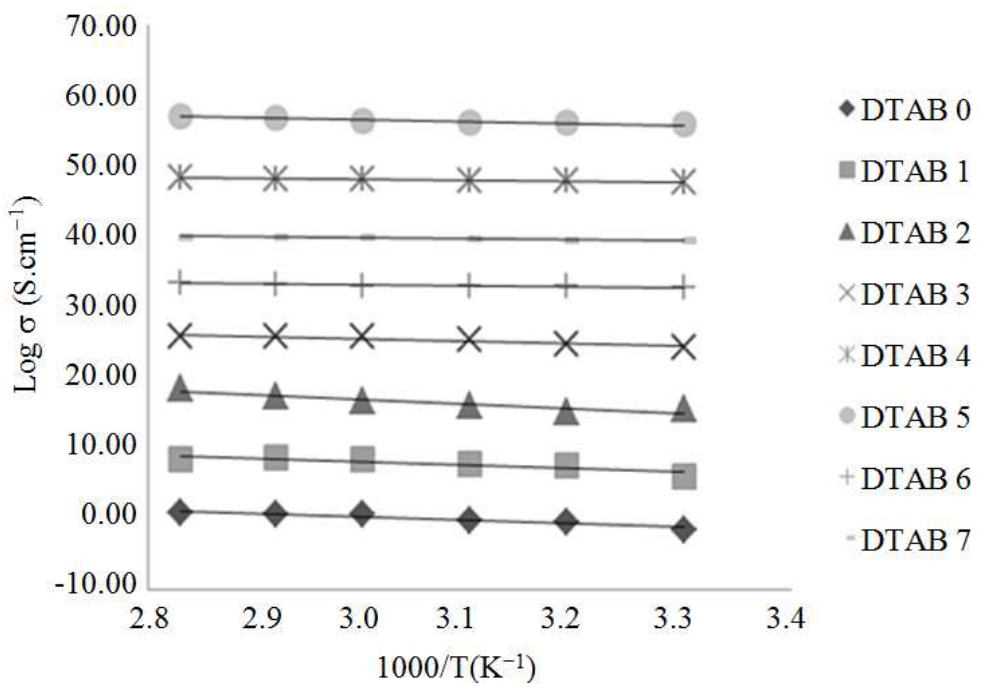

Fig. 2. Temperature dependence of conductivity for SBEs sample at different composition of DTAB (wt.\%) 


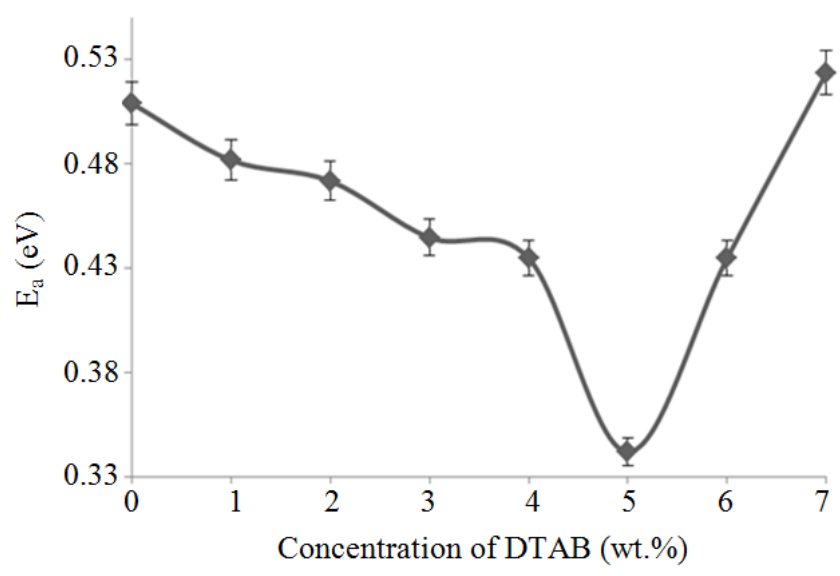

Fig. 3. Activation energy, $E_{a}$ versus composition of DTAB (wt.\%)

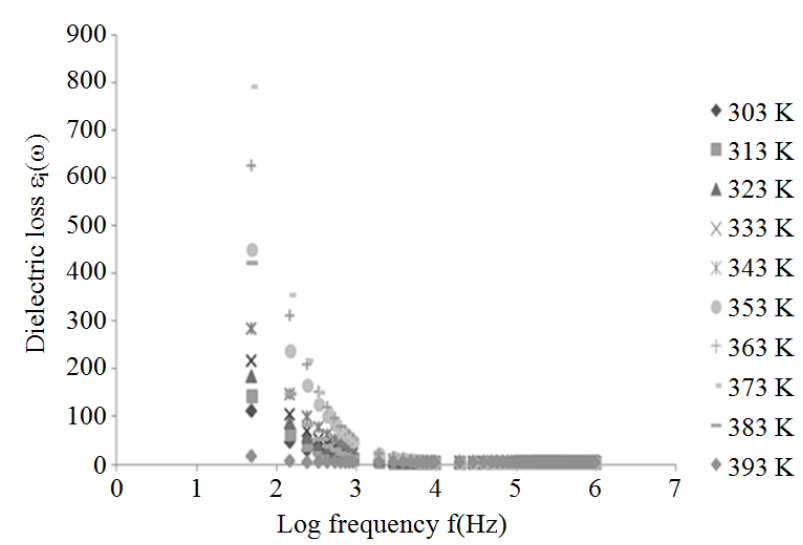

(a)

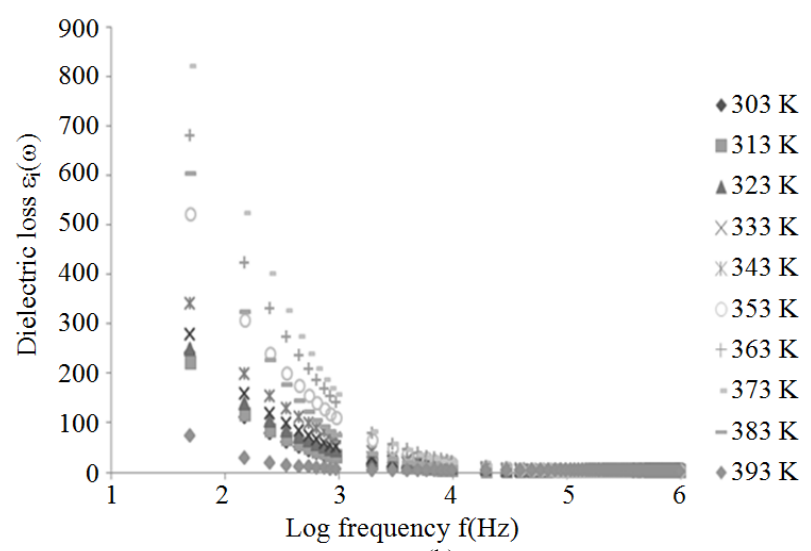

(b)

Fig. 4. (a) Dielectric constant versus log frequency for DTAB-5 (b) Dielectric loss versus log frequency for DTAB-5

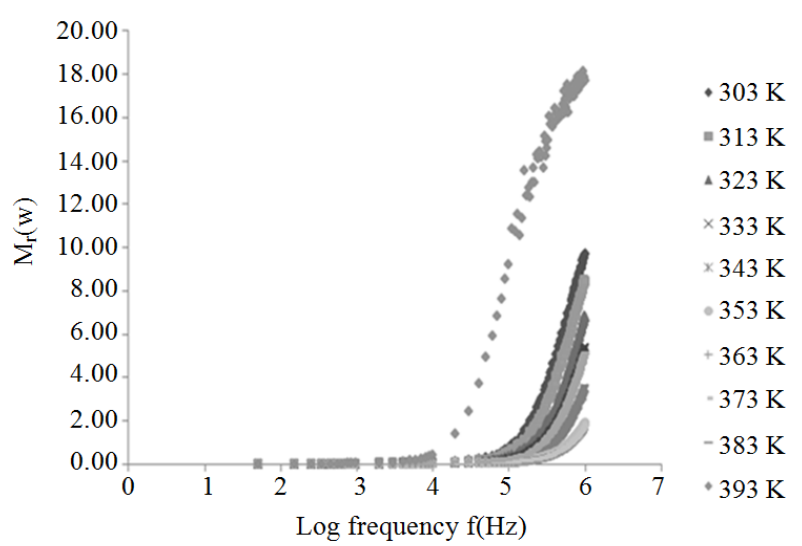

(a)

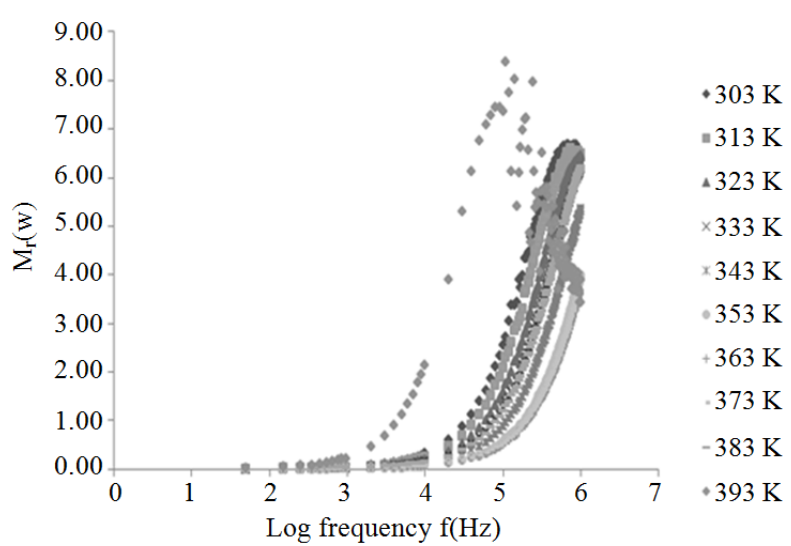

(b)

Fig. 5. (a) Real part of electrical modulus versus log frequency for DTAB-5 (b) Imaginary part of an electrical modulus versus log frequency for DTAB-5

Figure $4 \mathrm{a}$ and $\mathrm{b}$ shows the lowest dielectric constant and dielectric loss in the range of 3 to $6 \mathrm{~Hz}$ of DTAB-5. The appreciable relaxation peaks was not found in the range frequency that been used in this study. Both $\varepsilon_{r}$ and $\varepsilon_{i}$ have a sharp rise at the low frequencies due to the electrode polarization and space charge effects have occurred and confirming that as non-Debye dependence (Chai and Isa, 2011). 
According to Khiar and Arof (2010) the polarization that occurs due to the charge accumulation will lead to the decreasing in the value of dielectric loss. The increment of frequency consume will increase the rate of reversal of the electric field. As a result, no time for charge to build up at the interface. The increment of frequency consume will 'increase the rate of reversal of the electric field. As a result, no time for charge to build up at the interface.

\section{Modulus Studies}

In the modulus study, the real part of electrical modulus, $M_{r}$ and imaginary part of electrical modulus, $M_{i}$ was calculated by using the Equation 5 and 6 :

$$
\begin{aligned}
& M_{r}(\omega)=\varepsilon_{r} /\left(\varepsilon_{r}^{2}+\varepsilon_{i}^{2}\right) \\
& M_{i}(\omega)=\varepsilon_{i} /\left(\varepsilon_{r}^{2}+\varepsilon_{i}^{2}\right)
\end{aligned}
$$

Figure 5a and $\mathrm{b}$ show both $M_{r}$ and $M_{i}$ are low and nearest to zero at low frequency but it starts to increase as frequency increased from $3 \mathrm{~Hz}$ until $6 \mathrm{~Hz}$ with no relaxation peaks. According to (Khiar et al., 2006; Hafiza et al., 2014) the appearance of this long tail at low frequencies is perhaps due to the large capacitance applied with the electrodes which confirmed the nonDebye behavior in the SBEs system.

Modulus value will be increase with frequency due to the bulk effect (Carlson et al., 1997). Bulk effect has been discovered by (Gunn, 1963) there are two elements regarding to bulk effect: Transferred by electron and avalanche transit-time. In this research, the bulk effects were because of transferred by electron happen in the systems (Murayama et al., 1974).

\section{Conclusion}

Transparent Solid Biopolymer Electrolytes (SBEs) of $\mathrm{CMC} / \mathrm{CS}-\mathrm{DTAB}$ were prepared with no phase separation. The miscible blending of CMC with Chitosan (CS) doped with DTAB has improved the conductivity of the electrolyte from $3.15 \times 10^{-9}{\mathrm{~S} . \mathrm{cm}^{-1}}^{-}$to $1.86 \times 10^{-6}$ S.cm ${ }^{-1}$ and this systems show the highest ionic conductivity at room temperature $(303 \mathrm{~K})$. The ionic conductivity results as a function of temperature display an Arrhenius rule and the value of activation energy is capsized of conductivity. The dielectric study suggests that samples show non-Debye dependence. The performance of this SBEs system can be improvised by introducing plasticizer to the system.

\section{Acknowledgement}

All of the authors would like to thank the Ministry of Education Malaysia for the funding of this study through
Fundamental Research Grant Scheme (FRGS), Exploratory Research Grant Scheme (ERGS) and MyBrain 15 awarded.

\section{Funding Information}

Ministry of Education Malaysia for the funding of this study through Fundamental Research Grant Scheme (FRGS), Exploratory Research Grant Scheme (ERGS) and MyBrain15 awarded.

\section{Author's Contributions}

Nur Yasmin Abu Bakar: Participated in overall experiments from sample preparation untildata-analysis and contributed to the writing of the manuscript.

Nur Hafiza Mr. Muhamaruesa: Participated in further data-analysis.

Nur Ain Bashirah Aniskari: Participated in reporting data and eradicate the problem.

Mohd Ikmar Nizam Mohamad Isa: Participated in overall experiments from sample preparation untildataanalysis and contributed to the writing of the manuscript.

\section{Ethics}

This article is original and contains unpublished material. The corresponding author confirms that all of the other authors have read and approved the manuscript and no ethical issues involved.

\section{References}

Aziz, N.A.N., N.K. Idris and M.I.N. Isa, 2010. Solid polymer electrolytes based on methylcellulose: Ftir and ionic conductivity studies. Int. J. Polymer Analysis Characterizat., 15: 319-327.

DOI: $10.1080 / 1023666$ X.2010.493291

Bakar, N.Y. and M.I.N. Isa, 2014. Potential of ionic conductivity and transport properties solid biopolymer electrolytes based carboxy methylcellulose/chitosan polymer blend doped with dodecyltrimethyl ammonium bromide. Res. J. Recent Sci., 310: 69-74.

Baskaran, R., S. Selvasekarapandian, N. Kuwata, J. Kawamura and T. Hattori, 2006. Conductivity and thermal studies of blend polymer electrolytes based on PVAc-PMMA SBEs. Solid State Ion., 177: 2679-2682. DOI: 10.1016/j.ssi.2006.04.013

Buraidah, M.H. and A.K. Arof, 2011. Characterization of chitosan/PVA blended electrolyte doped with NH4I. J. Non-crystalline Solids, 357: 3261-3266. DOI: 10.1016/j.jnoncrysol.2011.05.021

Calvin, M., 1979. Petroleum plantations for fuel and materials. Bioscience, 29: 533-538.

DOI: $10.2307 / 1307721$ 
Carlson, C.E., C. Molina-Paris, J. Perez-Mercader and M. Visser, 1997. Schwinger's dynamical casimir effect: Bulk energy contribution. Phys. Lett. B, 395: 76-82. DOI: 10.1016/S0370-2693(97)00009-9

Chai, M.N. and M.I.N. Isa, 2011. Carboxyl methylcellulose solid polymer electrolytes: Ionic conductivity and dielectric study. J. Current Eng. Res., 1: 23-27.

Chai, M.N. and M.I.N. Isa, 2012. Investigation on the conduction mechanism of carboxyl methylcelluloseoleic acid natural solid polymer electrolyte. Int. J. Adv. Technol. Eng. Res., 2: 36-39.

Chai, M.N. and M.I.N. Isa, 2013. Electrical characterization and ionic transport properties of carboxyl methylcellulose-oleic acid solid polymer electrolytes. Int. J. Polymer Analysis Characterizat., 18: 280-286. DOI: 10.1080/1023666X.2013.767033

Chauhan, G.S. and H. Lal, 2003. Novel grafted cellulose-based hydrogel for water technologies. Desalination, 159: 131-138. DOI: $10.1016 / \mathrm{S} 0011-9164(03) 90065-8$

Gunn, J.B., 1963. Travelling-wave interaction between the optical modes of a polar lattice and a stream of charge carriers. Phys. Lett., 4: 194-195. DOI: 10.1016/0031-9163(63)90360-3

Utracki, L.A., 2002. Polymer Blends Handbook. 1st Edn., Kluwer Academic Publishers, Dordrecht ISBN-10: 1402011105, pp: 1442.

Hafiza, M.N., A.N.A. Bashirah, N.Y. Bakar and M.I.N. Isa, 2014. Electrical properties of carboxyl methylcellulose/chitosan dual blend green polymer doped with ammonium bromide. Int. J. Polymer Analysis Characterizat., 19: 151-158. DOI: $10.1080 / 1023666 X .2014 .873562$

Huang, H., P. He, N. Hu and Y. Zeng, 2003. Electrochemical and electrocatalytic properties of myoglobin and haemoglobin incorporated in carboxymethyl cellulose films. Bioelectrochemistry, 61: 29-38. DOI: 10.1016/S1567-5394(03)00057-4

Isiklan, N., M. Inal and M. Yigitoglu, 2008. Synthesis and characterization of poly (N-vinyl-2-Pyrrolidone) grafted sodium alginate hydrogel beads for the controlled release of indomethacin. J. Applied Polymer Sci., 110: 481-493. DOI: 10.1002/app.28577

Jung, B. O., S.J. Chung and S.B. Lee, 2006. Preparation and characterization of eugenol-grafted chitosan hydrogels and their antioxidant activities. J. Applied Polymer Sci., 99: 3500-3506. DOI: 10.1002/app.22974

Kadir, M.F.Z., Z. Aspanut, S.R. Majid and A.K. Arof, 2011. FTIR studies of plasticized poly(vinyl alcohol)chitosan blend doped with NH4NO3 polymer electrolyte membrane. Spectrochimica Acta Part A, 78: 1068-1074. DOI: 10.1016/j.saa.2010.12.051
Khiar, A.S.A. and A.K. Arof, 2010. Conductivity studies of starch-based polymer electrolytes. Ionics, 16: 123-129. DOI: 10.1007/s11581-009-0356-y

Khiar, A.S.A., R. Puteh and A.K. Arof, 2006. Conductivity studies of a chitosan-based polymer electrolyte. J. Phys. B. Condensed Matter, 373: 23-27. DOI: 10.1016/j.physb.2005.10.104

Khurmi, R.S. and R.S. Sedha, 2010. Materials Science. 1st Edn., S. Chand, New Delhi, ISBN-10: 8121901464, pp: 367.

Murayama, K., Y. Nakamura, A. Shibayama, A. Dohi and T. Ohmi et al., 1974. Planar-type gunn diode of inp. Jap. J. Applied Phys., 13: 662-666. DOI: $10.1143 /$ JJAP.13.662

Othman, M.F.M., A.S. Samsudin and M.I.N. Isa, 2012. Ionic conductivity and relaxation process in CMCG.A solid biopolymer electrolytes. J. Current Eng. Res., 2: 6-10.

Peng, Z. and F. Chen, 2010. Synthesis and properties of temperature-sensitive hydrogel based on hydroxyethyl cellulose. Int. J. Polymeric Mater., 59: 450-461. DOI: 10.1080/00914030903538637

Rajendran, S., O. Mahendran and T. Mahalingam, 2002. Thermal and ionic conductivity studies of plasticized PMMA/PVdF blend polymer electrolytes. Eur. Polymer J., 38: 49-55. DOI: $10.1016 / \mathrm{S} 0014-3057(01) 00140-9$

Ramlli, M.A., M.N. Chai and M.I.N. Isa, 2013. Influence of propylene carbonate as a plasticizer in CMC-OA based biopolymer electrolytes: Conductivity and electrical study. Adv. Materials Res., 802: 184-188. DOI: $10.4028 / w w w . s c i e n t i f i c . n e t / A M R .802 .184$

Rozali, M.L.H., A.S. Samsudin and M.I.N. Isa, 2012. Ion conducting mechanism of carboxy methylcellulose doped with ionic dopant salicylic acid based solid polymer electrolytes. Int. J. Applied Sci. Technol., 2: 113-121.

Samsudin, A.S. and M.I.N. Isa, 2012a. Characterization of carboxy methylcellulose doped with DTAB as new types of biopolymer electrolytes. Bull. Mater. Sci., 35: 1123-1131.

DOI: $10.1007 / \mathrm{s} 12034-012-0396-1$

Samsudin, A.S. and M.I.N. Isa, 2012b. Structural and electrical properties of carboxy methylcellulosedodecyltrimethyl ammonium bromide-based biopolymer electrolytes system. Int. J. Polymeric Materials, 61: 30-40. DOI: $10.1080 / 00914037.2011 .557810$

Samsudin, A.S., W.M. Khairul and M.I.N. Isa, 2012. Characterization on the potential of carboxy methylcellulose for application as proton conducting biopolymer electrolytes. J. Non-Crystalline Solids, 358: 1104-1112.

DOI: 10.1016/j.jnoncrysol.2012.02.004 
Sandoval, C., C. Castro, L. Gargallo, D. Radic and J. Freire, 2005. Specific interactions in blends containing chitosan and functionalized polymers. Molecular dynamics simulations. Polymer, 46: 10437-10442. DOI: 10.1016/j.polymer.2005.08.059

Selvasekarapandian, S., G. Hirankumar, J. Kawamura, N. Kuwata and T. Hattori, 2005. H solid state NMR studies on the proton conducting polymer electrolytes. Materials Lett., 59: 2741-2745. DOI: 10.1016/j.matlet.2005.04.018

Shukur, M.F., M.F.Z. Kadir, Z. Ahmad and R. Ithnin, 2012. Transport properties of Chitosan/PEO blend based proton conducting polymer electrolyte. Adv. Materials Res., 488-489: 114-117.

DOI: 10.4028/www.scientific.net/AMR.488-489.114

Sit, Y.K., A.S. Samsudin and M.I.N. Isa, 2012. Ionic conductivity study on Hydroxyethyl Cellulose (HEC) doped with $\mathrm{NH} 4 \mathrm{Br}$ based biopolymer electrolytes. Res. J. Recent Sci., 1: 16-21.
Vieira, D.F., C.O. Avellaneda and A. Pawlicka, 2007. Conductivity study of a gelatin-based polymer electrolyte. Electrochimica Acta, 53: 1404-1408. DOI: 10.1016/j.electacta.2007.04.034

Wach, R.A., H. Mitomo, F. Yoshii and T. Kume, 2001. Hydrogel of biodegradable cellulose derivatives. II. Effect of some factors on radiation-induced crosslinking of CMC. J. Applied Polymer Sci., 81: 3030-3037. DOI: 10.1002/app.1753

Wan, Y., K.A.M. Creber, B. Peppley and V.T. Bui, 2006. Chitosan-based electrolyte composite membranes: II. Mechanical properties and ionic conductivity. J. Membrane Sci., 284: 331-338. DOI: $10.1016 /$ j.memsci.2006.07.046 